\title{
LIV. The emission-function of a body emitting a line-spectrum
}

\section{Alfred W. Porter}

To cite this article: Alfred W. Porter (1901) LIV. The emission-function of a body emitting a linespectrum , Philosophical Magazine Series 6, 2:11, 573-574, DOI: $10.1080 / 14786440109462721$

To link to this article: http://dx.doi.org/10.1080/14786440109462721

曲 Published online: 08 Jun 2010.

Submit your article to this journal $\pi$

Џll Article views: 2

Q View related articles $\sqsubset$ 


\section{[ 573 ]}

\section{The Emission-Function of a Body emitting a} Line-Spectrum. By AlFRed W. PORTER*.

WHATEVER the emission-function for the energy radiated from snch a body may be, it must satisfy the following conditions:-

i. It must vanish for all values of wave-length $(\lambda)$ except those which correspond to the spectral lines.

ii. That part of the function which determines the position of these lines must be independent of the temperature.

An attempt has been made by P. G. Nutting (Astrophysical Journal, Oct. 1900, and Phil. Mag. Oct. 1901) to supply such a function; and he gives a series-form each term of which corresponds to a spectral maximum of infinite value.

It has occurred to me that in the case of Hydrogen the following form is preferable, inasmuch as the difficulty of infinite values does not enter and, moreover, a single term is sufficient to represent all the lines in the elementary linespectrum instead of a summation of 13 terms :-

$$
\mathrm{E}=\mathrm{F} \sin ^{2}[\mathrm{~N} v] / \sin ^{2} v
$$

where $\mathrm{F}$ is a factor to be presently examined;

$$
v=\pi \sqrt{\frac{4 p_{0}}{p_{0}-p}}
$$

where $p_{0}=27418.3 ; \mathrm{N}$ is any large integer, for example 1000 or 10,000, and $p$ (=oscillation-frequency) may assume any value for which $v$ is real.

The way in which this formula is based on Balmer's formula for the position of the spectral lines will be very evident; while the march of $\mathrm{E}$ as $v$ varies may at once be pictured by recalling the similar formula which occurs in connexion with diffraction-gratings.

$\mathrm{E}$ will be of quite negligible value for most values of $p$, but suddenly mounts to the value $\mathrm{N}^{2} \mathrm{~F}$ for the wave-length of each of the lines given by Balmer's formula : it therefore represents the position of the maxima to the accuracy of the latter formula, viz. one part in 50,000 .

To represent the fact that the lines are not of equal intensity the factor $\mathrm{F}$ must depend on $\lambda$ and $\mathrm{T}$; and in the absence of sufficient knowledge concerning the probable form of $\mathrm{F}$, I can only suggest that these enter in the same way as in the expression for the radiation from an absolutely black body. Thus adopting Wien's formula, the emission-function will be

$$
\mathrm{E}=\mathrm{C}[\sin \mathrm{N} v / \sin v]^{2} p^{5} \exp .(-c p / \mathrm{T}) .
$$

Similar formulæ may be written down for other substanees

* Communicated by the Author. 
based on Kayser and Runge's formulæ; but now a single term will represent only one of the several serIas of lines which accompany one another ; but a summation of not more than six terms will be adequate to include all the known lines in their spectra. Thus, making use of Rydberg's formula

and putting

$$
\begin{gathered}
p=p_{0}-\frac{\mathrm{A}}{(m+e)^{2}}, \\
v=\pi\left\{\sqrt{\frac{\mathrm{A}}{p_{0}-p}-e}\right\},
\end{gathered}
$$

the formula given above is capable of forming the basis of an expression representing the distribution of energy in any one series of the majority of spectra.

I have no suggestion to offer as to the rationale of this formula; but suggest it as an empirical one which may possibly be useful in representing the energy distribution in a line-spectrum. Experimental data on the relative intensity of the spectral lines are at present too scanty to test its value.

Physical Department,

University College, London.

LV. Notices respecting New Books.

An Elementary Treatise on Dynamics, containing Applications to Thermodynamics, with numerous Examples. By BeNsamin Williamson, Sc.D., F.R.S., Senior Fellow of Trinity College, Dublin; and Francis A. Tarleton, Sc.D., LL.D., Fellow of Trinity Collige, and Professor of Natural Philosophy in the University of Dublin. Third Edition, Revised and Enlarged. London : Longmans, Green, \& Co. 1900. Pp. xvi +560.

$\mathrm{WE}$ know of no other work on dynamics in the English language which can compare in general usefulness to the student with the work before us, now in its third edition. The science of dynamics is admittedly one of the most difficult and intricate branches of knowledge, and on account of its fundamental character indispensable to all students of nature. The number of elementary books on dynamics published within the last quarter of a century is quite appalling, but the gap between the purely elementary and the most advanced type of text-book on this subject is far from being filled, and we have some difficulty in recollecting many satisfactory text-books of the intermediate class. The late Professor Tait's article on "Mechanics" in the Encyclopoedia Britannica, now obtainable in book-form as a treatise on "Dynamics," is a masterly example of clearness and elegance of treatment, but it does not meet the wants of the student in every respect, as there are no examples by means of which he would be enabled to test his knowledge, skill, and ingenuity ; and attempting to learn dynumics without working out numerous examples is as hopeless as trying to learn pure mathematies by the same method. Ouse very important feature of the book under review is the 